\title{
A CADAVERIC STUDY ON VARIATIONS OF THE CYSTIC ARTERY IN THE DEPARTMENT OF PATHOLOGY, AT THE UNIVERSITY TEACHING HOSPITALS, LUSAKA, ZAMBIA
}

Isaac Sing `ombe ${ }^{1}$, Vivienne Nambule ${ }^{1}$, Fridah Mutalife ${ }^{1}$, Sikhanyiso Mutemwa ${ }^{1}$, Elliot Kafumukache ${ }^{1}$, Krikor Erzingastian²

${ }^{1}$ Department of Anatomy, School of Medicine, University of Zambia, Lusaka, Zambia

${ }^{2}$ Departments of Surgery and Anatomy, School of Medicine, University of Zambia, Lusaka, Zambia

Correspondence to Mr. Isaac Sing'ombe. Email: isingombe@gmail.com

\section{ABSTRACT}

The main source of blood supply to the gall bladder is the cystic artery which is a branch of the right hepatic artery. Anatomical variations of the cystic artery are frequent. Thus, careful dissection of the Calot's triangle is necessary for conventional and laparoscopic cholecystectomy. The knowledge of variations of the origin, course, and length of the cystic artery is important for the surgeon as bleeding from the cystic artery during cholecystectomy can lead to death. Thirty-two post-mortem human cadavers at the University Teaching Hospitals, Pathology Department, Lusaka were dissected and examined over a period of five weeks, to establish the origin, length and course of the cystic artery. And to establish the relationship of the cystic artery to the cystic duct. Out of the 32 human cadavers, the cystic artery was found to be originating from the right hepatic artery in twenty-eight (87.5\%), from hepatic artery proper in three (9.4\%) and from the left hepatic artery in one (3.1\%). In the twenty-nine $(90.6 \%)$ cadavers dissected, only one cystic artery was identified and in three $(9.4 \%)$ others there were two arteries detected. The cystic artery length ranged from $2-6 \mathrm{~cm}$ (mean 3.56士 $1.0285 \mathrm{~cm}$ ). The cystic artery was found to be inside Calot's triangle in twenty-seven (84.3\%) while in three $(9.4 \%)$ cadavers it was outside the Calot's triangle. The cystic artery was found to be passing supero-medial to the cystic duct in thirty (93.7\%) cadavers while in two $(6.3 \%)$ the cystic artery was passing anterior to the cystic duct. Demographic characteristic (gender and age) had no statistically significant association to variations of cystic artery $(p>0.005)$. Five $(18.5 \%)$ of males had variants of cystic artery and no females had variants of the cystic artery. Variations of the cystic artery origin, length, its course through the Calot's triangle and its relation to the cystic duct are common. Knowledge of these variations is important and helpful in preventing and controlling haemorrhage or avoiding other complications during conventional and laparoscopic cholecystectomy.

Key words: Cystic artery, Variations, Cholecystectomy, Calot`s triangle

\section{INTRODUCTION}

The chief source of blood supply to the gallbladder and the cystic duct is the cystic artery (Tejaswi et al., 2013). The cystic artery (CA) is a single vessel that originates from the right branch of the proper hepatic artery (PHA). It usually passes through the hepato-biliary triangle or Calot's triangle, which is bounded superiorly by the inferior surface of the liver, inferiorly by the cystic duct and medially by the common hepatic duct (Polgui et al., 2014).

Anatomical variations of the cystic artery are commonly encountered during cholecystectomy. In Approximately $80 \%$ of individuals, the cystic artery arises from the right hepatic artery. The other origins include the left hepatic artery, proper hepatic artery, common hepatic artery, 
gastroduodenal artery, superior pancreaticoduodenal artery and superior mesenteric artery (Sarkar and Roy, 2000).

A good knowledge of Calot's triangle is important for conventional and laparoscopic cholecystectomy. Calot's triangle is an important imaginary referent area for biliary surgery. Cystic artery bleeding is a wearisome complication during laparoscopic cholecystectomy, which increases the rate of conversion to open surgery. If surgery is performed incorrectly, injury to the extra-hepatic bile duct or intra-abdominal organs may occur (Ding et al., 2007). Laparoscopic cholecystectomy has been accepted as the preferred method of treatment of gall bladder stones in healthy individuals all over the world.
In Zambia, at the University Teaching Hospital (UTH), laparoscopic cholecystectomy is being carried out for treatment of cholelithiasis. Some of the complications experienced by the surgeons during cholecystectomy were; injury to the liver and nearby structures such as the stomach, mistaking the right hepatic artery as a cystic duct and bleeding. For safe and uneventful cholecystectomy, especially by means of laparoscopic techniques, it is important to be familiar with anatomic variations in the hepatobiliary arterial system (Polgui et al., 2014). The findings of this study will help surgeons minimize accidental injury to the bile duct and cystic artery, avoid haemorrhagic complications and mortality during cholecystectomy.

\section{METHODOLOGY}

This was a descriptive cross-sectional study design in which 32 post-mortem human cadavers at the University Teaching Hospitals, Pathology Department, Lusaka, were dissected and examined over a period of five weeks. A data collection form was used as a tool to gather data and sample selection was done through systematic sampling. Data was entered and analyzed using Statistical Package for Social Sciences Statistics, version 22.0 (SPSS). Chisquare and Fisher's tests were used to test association between variables. The cadavers dissected were aged between 22 and 66 years (mean 36.06 \pm 11.992 ) and of the 32, 27 were males and 5 females.

The peritoneal cavity was opened and explored. The lesser omentum was dissected and the sub- hepatic region of the abdomen was exposed. The fundus of the gall bladder was held with a swab or hand and pulled in a cephalic, lateral and anterior direction. After this, the foramen of Winslow was identified and then Foley catheter or artery forceps was placed through the opening as a guide. The peritoneum covering the Calot's Triangle was carefully opened, exposing the cystic duct and the cystic artery. The cystic artery was then followed to its origin. The origin, length, and course of the cystic artery along with its position with reference to Calot's triangle were noted and recorded. Length was measured using a Vernier Caliper.

\section{RESULTS}

Out of the 32 human cadavers, the cystic artery was found to be originating from the right hepatic artery in twenty-eight (87.5\%), from hepatic artery proper in three $(9.4 \%)$ and from the left hepatic artery in one (3.1\%). In the twenty-nine (90.6\%) cadavers dissected, only one cystic artery was identified and in three $(9.4 \%)$ others there were two arteries detected. 


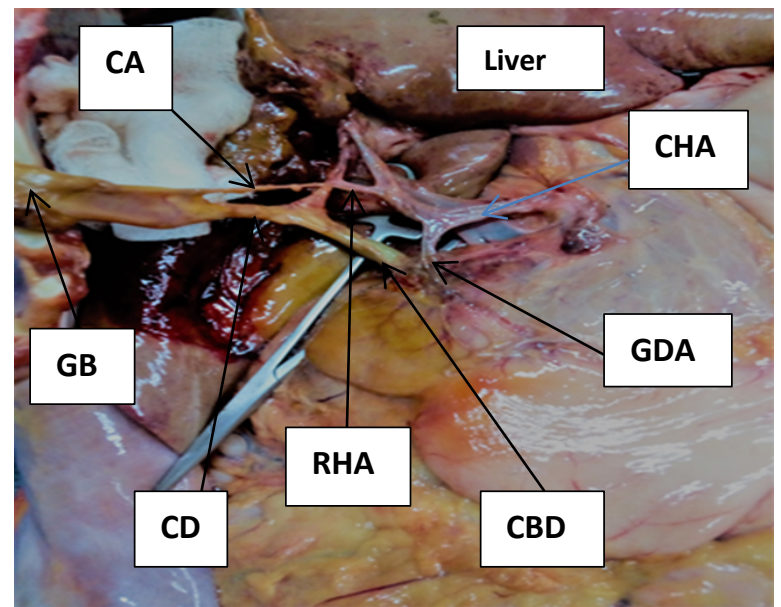

Figure 1: Cystic artery (within the Calot's triangle) originating from right hepatic artery.

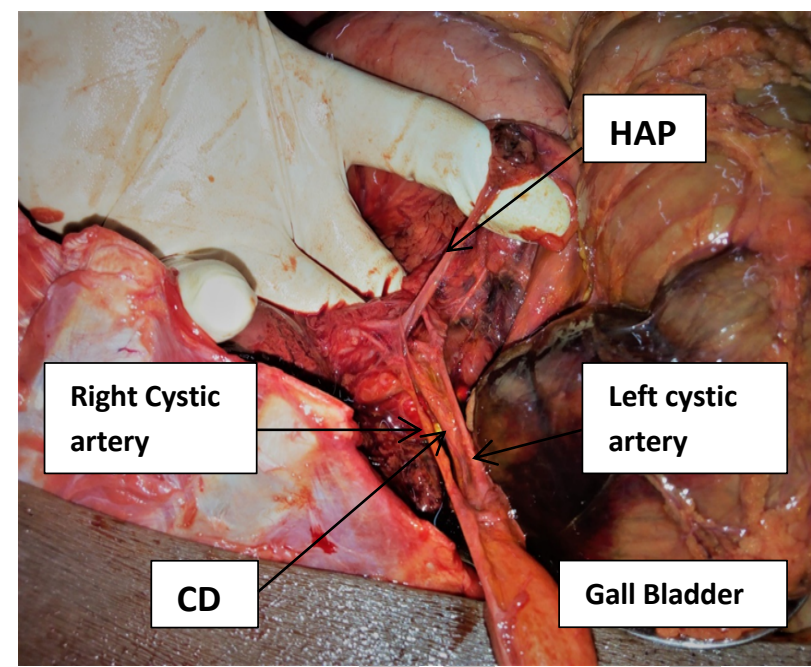

Figure 2: Anomalous origin of the CA (Double cystic artery) from the right hepatic artery (within Calot's triangle) and hepatic artery proper. Anomalous course of the CA originating from the hepatic artery proper (outside Calot' $\mathrm{s}$ triangle)

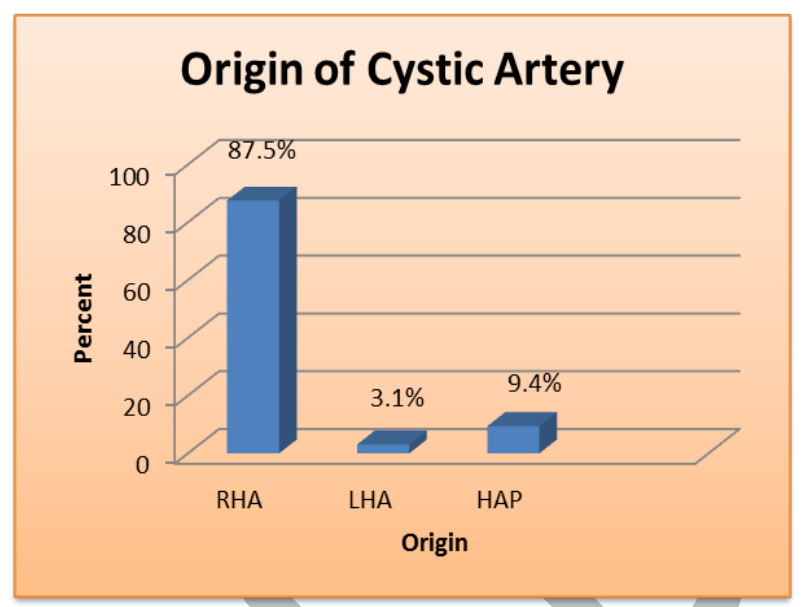

Figure 3: Origin of the cystic artery

The cystic artery length ranged from $2-6 \mathrm{~cm}$ (mean $3.56 \pm 1.0285 \mathrm{~cm}$ ).

\section{Table 1: Length of Cystic Artery}

\begin{tabular}{|l|l|l|}
\hline Characteristics & Number & Percentage \\
\hline $2-4 \mathrm{~cm}$ & 25 & 78.1 \\
\hline Above $4 \mathrm{~cm}$ & 7 & 21.9 \\
\hline Total & $\mathbf{3 2}$ & $\mathbf{1 0 0}$ \\
\hline
\end{tabular}

The cystic artery was found to be inside Calot's triangle in twenty-seven (84.3\%) while in three $(9.4 \%)$ cadavers it was outside the Calot's triangle.

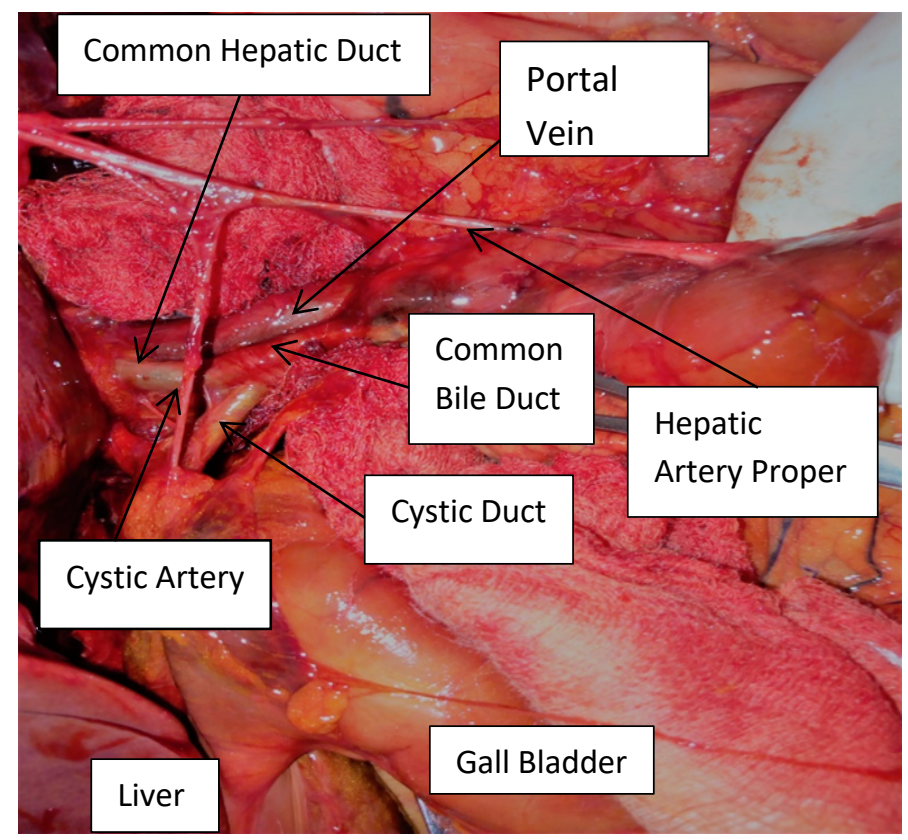

Figure 4: Anomalous origin of the cystic artery from the hepatic artery proper 
The cystic artery was found to be passing supero-medial to the cystic duct in thirty $(93.7 \%)$ while in two (6.3\%) cadavers the cystic artery was passing anterior to the cystic duct
Demographic characteristics (gender and age) had no statistically significant association to variations of cystic artery $(p>0.005)$. Five $(18.5 \%)$ of males had variants of cystic artery and no females had variants of the cystic artery.

\section{DISCUSSION}

In the current study, it was noted that the commonest origin of the cystic artery was the right hepatic artery in twenty-eight (87.5\%) cadavers. Variations in the origin of the cystic artery can be described on embryological basis. The cystic artery can arise from the right hepatic artery, left hepatic artery, hepatic artery proper, middle hepatic artery, gastroduodenal artery or the aorta. An operating surgeon must be familiar with these variations to avoid inadvertent injuries during control, ligation, clipping and division of vessels and the consequent morbidity associated with surgery (Dandekar $\mathrm{U}$ and Dandekar $\mathrm{K}$, 2016). This current study agrees with the other studies as the most common origin of the cystic artery was the right hepatic artery.

In the current study the cystic arteries were observed to be passing through the Calot's triangle in twenty- seven $(84.3 \%)$ while three $(9.4 \%)$ of the cystic arteries were passing outside the Calot's triangle (Table 3).

Table 2: Comparison of origin cystic artery with other studies

\begin{tabular}{|c|c|c|c|c|c|c|c|c|c|}
\hline No & & $\begin{array}{l}\text { Number } \\
\text { of }\end{array}$ & & & & & & & \\
\hline & & & RHA & HAP & LHA & LP & GDA & CHA & SMA \\
\hline 1 & Present study & 3 & $28(87.5 \%)$ & $3(9.4)$ & $1(3.1 \%)$ & 0 & 0 & 0 & 0 \\
\hline 2 & Aristole $^{1}$ & 40 & $38(95 \%)$ & $2(5 \%)$ & 0 & 0 & 0 & $1(2.5 \%)$ & 0 \\
\hline 3 & Tejaswi et $\mathrm{al}^{2}$ & 100 & $92(92 \%)$ & 0 & $1(1 \%)$ & 0 & $1(1 \%)$ & 0 & 0 \\
\hline 4 & Pushpalatha $^{1}$ & 50 & $27(54 \%)$ & $11(22 \%)$ & 0 & 0 & $4(8 \%)$ & $6(12 \%)$ & $2(4 \%)$ \\
\hline
\end{tabular}


Table 3: Comparison of the cystic artery course to the Calot's triangle with other studies

\begin{tabular}{|c|c|c|c|c|}
\hline \multirow[t]{2}{*}{ No } & \multirow[t]{2}{*}{ Studies } & \multirow{2}{*}{$\begin{array}{l}\text { Number of } \\
\text { Cadavers }\end{array}$} & \multicolumn{2}{|c|}{ Relationship to the Calot's Triangle } \\
\hline & & & Inside & Outside \\
\hline 1 & Present Study & 32 & $27(84.3 \%)$ & $3(9.4 \%)$ \\
\hline 2 & Badshah et $\mathrm{al}^{3}$ & 65 & $44(68 \%)$ & $21(32 \%)$ \\
\hline 3 & Futara et $\mathrm{al}^{2}$ & 110 & $89(81 \%)$ & $21(19 \%)$ \\
\hline 4 & R Gawali $^{1}$ & 30 & $27(90 \%)$ & $3(10 \%)$ \\
\hline
\end{tabular}

This current study agrees with the other studies as the cystic artery was mostly found inside the Calot $s$ triangle. The current finding emphasizes the importance of knowledge of Calot's triangle and the variations thereof.

In the current study the mean length of the cystic artery was $3.56 \mathrm{~cm}$ and ranged from $2 \mathrm{~cm}$ to $6 \mathrm{~cm}$. Surgeons should be aware of such short type variations as the length has a bearing on the type of clip to be used and the security with which a ligature is applied to the cystic artery (Table 4).

Table 4: Comparison of Length of cystic artery with other studies

\begin{tabular}{|l|l|l|l|l|}
\hline No & Studies & $\begin{array}{l}\text { Number of } \\
\text { Cadavers }\end{array}$ & Mean & Average length (Range) \\
\hline 1 & Present Study & 32 & $3.56 \mathrm{~cm}$ & $2-6 \mathrm{~cm}$ \\
\hline 2 & Tejaswi et al $^{2}$ & 100 & $1.76 \mathrm{~cm}$ & $0.37-4.2 \mathrm{~cm}$ \\
\hline 3 & Dandekar et al $^{1}$ & 82 & $1.69 \mathrm{~cm}$ & $0.2-5.5 \mathrm{~cm}$ \\
\hline
\end{tabular}

This current study is not in agreement with the other studies as the cystic artery length in a Zambian population is longer.

In the current study, thirty (93.7\%) cadavers had the cystic artery superomedial to the cystic duct and in two cadavers $(6.3 \%)$ it was anterior to the cystic duct. The findings of the current study are different from the ones found by Gawali (2014) were the cystic artery was noted to be passing anterior to the cystic duct in three (10\%) and in twenty-seven (90\%) cadavers it was not related to the cystic duct. Knowledge of the relation of the cystic artery to the cystic artery is important in preventing bile duct leakage, bleeding and for easy location of the cystic artery.

In conclusion, there were variations of the cystic artery in the liver specimens studied at the University Teaching Hospitals, Lusaka, Zambia. The cystic artery was found to be commonly originating from the right hepatic artery in twenty-eight cadavers (87.5\%). The mean length was $3.56 \pm 1.0285 \mathrm{~cm}$, cystic artery was found to be inside Calot's triangle in twenty-seven $(84.3 \%)$, three cadavers $(9.4 \%)$ it was outside Calot's triangle and was passing supero-medial to the cystic duct in thirty cadavers (93.7\%), two cadavers $(6.3 \%)$ the cystic artery was passing anterior to the cystic duct.

Knowledge of these variations is important and helpful in preventing and controlling haemorrhage or avoiding other complications during conventional and laparoscopic cholecystectomy.

\section{ACKNOWLEDGEMENT}

I wish to appreciate Ministry of Health for the financial support, Professor K. Erzingatsian and Dr E. Kafumukache for their guidance in the development of this study. Their guidance allowed me to bring the study to where it is today, making it possible for the reader to benefit. Finally, my greatest thanks go to my family and friends for their support and encouragement during this study.

Ethical approval: ERES Converge 


\section{REFERENCES}

1. Andall R, Matusz P, Du Plessis M, Ward R, Tubbs RS, Loukas M 2016. The clinical anatomy of cystic artery variations: a review of over 9800 cases. Surgical Radiological Anatomy.Jul;38(5):529-39. doe: 10.1007/s00276-015-1600-y.

2. Aristotle $S$ 2014. Variations in origin and course of cystic artery and its relations to Calot's triangle with its clinical implications. OA Anatomy 2014 Jul 18;2(2):17.

3. Bakheit M A 2009. Prevalence of variations of the cystic artery in the Sudanese. La Revue de

4. Sante de la Mediterranee Orientale East Mediterrian Health J:15(5):1308-1312.

5. Chen T.H, Shyu J.F, Chen C.H, Ma K.H, Wu C.W, Lui W.Y, Liu J.C 2000. Variations of the cystic artery in Chinese adults. Surg Laparosc Endosc Percutaneous Tech. V10:154-157.

6. Dandekar U, Dandekar K 2016. Cystic Artery: Morphological Study and Surgical Significance. Anatom Res Int.7201858.

7. Ding Y.M, Wang B, Wang W.X, Wang P, Ya J.S 2007. New classification of the anatomic variations of cystic artery during laparoscopic cholecystectomy. World J Gastroenterol. 13:562 9-5634.

8. Efrain A. Miranda, 2016, Triangle of Calot, Retrieved from http://clinical anatomy.com>mtd $>739$ triangle of Calot.

9. Eyni H, Pasbakhsh P, Azimi A, Behzadi Fard S 2015. Case Report: Variation of the Gall Bladder Vasculature including Double Cystic Arteries. ASJ:12(1):51:55.

10. Futara G, Ali A, Kinfu Y (2001). Variations of The hepatic and cystic arteries among Ethopians. Ethiop Med J.2001;39:133-142.

11. Gawali R. A 2014. A study on variations of origin and course of cystic artery and its relation to the Calot's triangle. International Journal of Medical and Pharmaceutical Sciences.;5(3):15-19.

12. Masroor Badshah, Soames R, Nawab J, Hasnain J 2016. The anatomical relationship of cystic artery to Calot's triangle. 199J. Med. Sci. (Peshawar) 24: Retrieved from http://www.researchgate.net/scientific

13. Polguj M, Podgórski M, Hogendorf P, Topol M 2014.Variations of the hepatobiliary vasculature including coexistence of accessory right hepatic artery with unusually arising double cystic arteries: case report and literature review. Ana Sci Int,89(3): 195-198.

14. Pushpalatha K., Shamasundar N. M 2010. Variation in the origin of cystic artery. Journal of Anatomical Society of India.;59(1):35-37.

15. Sarkar A.K, Roy TS 2000. Anatomy of the cystic artery arising from the gastroduodenal artery and its choledochal branch-a case report. J Anat. 197:503-506.

16. Tejaswi H. L., Dakshayani K. R., Ajay N 2013. Prevalence of anatomical variations of Cystic artery in South Indian cadavers. International Journal of Research in Medical Sciences:1: 424428. 